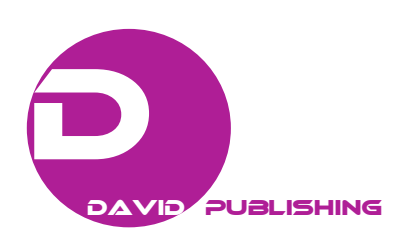

\title{
Safety Aspects of Line Markings on Two-Lane Low-Volume Narrow Roads in Virginia
}

\author{
Young-Jun Kweon, In-Kyu Lim, Lance E. Dougald and Benjamin H. Cottrell \\ Virginia Department of Transportation, Virginia Transportation Research Council, Charlottesville VA 22903, USA
}

\begin{abstract}
Pavement line markings are designed to provide drivers with visual clues for safe driving, and their installation is generally determined based on roadway width, traffic volume and functional classification. In general, for two-lane roadways, the Virginia Department of Transportation currently installs a centerline pavement marking on roads that have a minimum traffic count of 500 vehicles per day and a minimum width of $18 \mathrm{ft}$. This study examined the safety aspects of line markings on low-volume (3,000 vehicles per day or less) narrow ( $20 \mathrm{ft}$ or less) roads in Virginia. Four ways of measuring safety performance were employed. Crash frequency, density, rate and safety performance functions were used for those roads under four line marking types: no lines, a centerline only, edge lines only and both lines. Based on five years (2004 2008) of crash data on 4,797 road segments in Virginia, the study found no statistical difference between the presence and absence of a centerline and/or edge lines on the low-volume narrow roads. Omitted factors, such as curvature and speeds, might have some influence on the findings. By examining the age distributions of drivers in the crashes, it is conjectured that adding line markings can plausibly be inferred to provide safety benefits for teen drivers.
\end{abstract}

Key words: Line marking, highway safety, performance measure, teen drivers.

\section{Introduction}

Pavement line markings are designed to provide road users with continuous visual clues for safe driving, leading to enhanced highway safety. Thus markings are installed on a majority of roads, but not all roads. For example, roads with a low traffic volume and narrow width are often found without a centerline, edge lines or either. The decision on whether to install centerline and edge line markings is generally based on three characteristics of a road: road functional type, travel width and traffic volume.

The MUTCD (Manual on Uniform Traffic Control Devices for Streets and Highways) [1] is frequently referenced for a line marking decision and provides directives and guidance for the use of centerlines and edge lines based on roadway classification, width and average daily traffic. For example, for rural arterials

Corresponding Author: Young-Jun Kweon, Ph.D., P.E., senior research scientist, research fields: highway safety, traffic operations, performance measurement and evaluation, behavior study and policy analysis and applied statistics. E-mail: Young-Jun.Kweon@VDOT.virginia.gov. carrying at least 3,000 vpd (vehicles per day), centerline and edge line markings should be placed on such roads that are at least $18-\mathrm{ft}$ wide and at least $20-\mathrm{ft}$ wide, respectively. For roads carrying less than 3,000 vpd and/or are 16-ft wide, engineering judgment and/or study is recommended to determine the use of these markings.

Many studies have attempted to examine the safety effects of different types of line markings. Beneficial effects of edge lines on rural two-lane roads were reported in Texas [2]. Tsyganov et al. [2] found reductions in crash occurrences of up to $26 \%$, with the highest reductions on curved roads with a lane width of $9 \mathrm{ft}$ to $10 \mathrm{ft}$. In their follow-up study [3], they found that the average speed of traveling vehicles was increased by $5 \mathrm{mph}$, the average lateral fluctuation of the vehicles was reduced by $20 \%$, and vehicles moved toward the pavement edge by an average of $20 \mathrm{in}$.

An effect of edge lines on a vehicle's traveling speed in Louisiana was found to be different from that in Texas. Sun and Tekell [4] examined the effects of edge lines on rural, 20 22-ft wide, two-lane roads carrying 
about 90 to $1,900 \mathrm{vpd}$. They found that the presence of edge lines exerted little to no influence on traveling speeds. However, an effect similar to that in Texas was found when examining the lateral position of vehicles since the distribution of the observed vehicles became more compacted, especially during nighttime, after edge lines were installed.

Kusano and Gabler [5] found that the presence of lane markings was associated with a detrimental effect on injury severity for road departure crashes. This unexpected effect of lane markings was argued to be attributable to a lower seat belt use; Drivers at crashes on roads with no lane markings were found to wear seat belts less often ( $42 \%$ ) compared to those on roads with such markings $(67 \%)$.

Using meta-data analyses on results extracted from many studies, Van Driel et al. [6] concluded that effects of a centerline on speeds are related to those of edge lines, suggesting confounding effects of the two types of line markings on driving speeds. They found an increase in traveling speeds after edge lines was installed on roads that previously had no lines and a decrease in speeds after edge lines replaced a centerline. However, the effects of adding edge lines to a road with a centerline were not well understood.

For two-lane roads, the VDOT (Virginia Department of Transportation) typically installs a centerline where there is at least $18 \mathrm{ft}$ of pavement width and carrying $500 \mathrm{vpd}$ or more. Edge lines are installed where there are a centerline, no curb and gutter, and at least $20 \mathrm{ft}$ of pavement width [7]. Thus the VDOT policy on line markings is different from the warrants of the MUTCD. This is mainly because VDOT maintains its secondary road system, of which many roads are classified as local roads. The MUTCD's warrants address only arterials. Considering current levels of road maintenance demands and limited funds not keeping up with those demands, there is question as to the benefits of continuing to install line markings on low-volume (i.e., 3,000 vpd or less) and narrow (i.e., $20 \mathrm{ft}$ or less of pavement width) roads in Virginia.
In this respect, this study attempted to shed light on the potential safety aspects of line markings on low-volume narrow paved roads in Virginia. Specifically, the researchers examined three safety performance measures (crash frequency, density and rate) and SPFs (safety performance functions) for those roads under four types of line marking scenarios: (1) no lines; (2) a centerline only; (3) edge lines only; (4) a centerline and edge lines. The study focused on rural two-lane two-way undivided road segments with a pavement width of $20 \mathrm{ft}$ or less and an AADT (average annual daily traffic) of 3,000 vpd or less. Five years (2004 2008) of crash data were used in conjunction with traffic volume and a line marking inventory.

\section{Data}

Acquisition of inventories of pavement markings on the narrow low-volume roads was attempted using VDOT's database and internal files; However, it was learned that the inventories in some VDOT districts were incomplete (e.g., missing or nonexistent in some districts) or not current (e.g., 10 years old). Therefore, a new database for this study was created, using multiple data sources including subsystems of VDOT's HTRIS (Highway Traffic Records Information System) database and Google Earth.

VDOT maintains an Oracle database of HTRIS containing detailed records of historical roadway information that is used for internal and external management and reporting. HTRIS consists of 10 subsystems storing the highway and traffic characteristics of about 61,000 miles of public roads in Virginia. Three subsystems were used to form the 5-year data for the study: RDI (Roadway Inventory), ACC (Accident) and TMS (Traffic Monitoring System). A set of SQL (Structure Query Language) codes was used to identify and extract rural two-lane road segments between $16-\mathrm{ft}$ and $20-\mathrm{ft}$ wide from RDI, and crash history records from ACC and AADT from TMS were added to the identified segments. An inventory of pavement line markings was created using 
Google Earth and was later merged to the segments. The 10-step procedure used to develop the study database is provided in Ref. [8].

Approximately 4,800 segments of two-lane undivided paved roads with width of $20 \mathrm{ft}$ or narrower carrying 3,000 vpd or less are included in the study data. Table 1 shows basic statistics regarding the AADTs and crash rates of these segments. Among the segments, over $70 \%$ are $20-\mathrm{ft}$ wide, about $23 \%$ are $18-\mathrm{ft}$, and the remaining $4 \%$ are $16-\mathrm{ft}$. Slightly over one half of the segments have both centerline and edge lines, $43 \%$ have no lines, $5 \%$ have a centerline only, and less than $1 \%$ have edge lines only. AADTs appear to vary by width and line marking type. Segments with both lines or a centerline only tend to carry more traffic than the other marking types. Segments with a $16-\mathrm{ft}$ width tend to carry more traffic than those with an $18-\mathrm{ft}$ or 20 -ft width. Segments with a centerline only or both appear to have higher crash rates than those with the other line marking types, which could be linked to the traffic volume pattern: For example, 16-ft, 18-ft and 20 -ft segments with no lines were found to carry 2.6, 8.3 and 8.3 times more traffic than those with both lines, respectively. Only 18 segments had only edge lines, thus the sample size deemed to be too small for reliable statistical analyses.

\section{Methods}

Three safety performance measures frequently used in practice were adopted to assess the safety performance of the line markings: (1) crash frequency; (2) crash density; (3) crash rate. In practice, these three measures are typically used for reporting the safety performance of a program, treatment and project. An SPF relating crash frequency to AADT and segment length in an exponential function was also used in addition to the three measures. Thus, a total of four methods of measuring safety performance were employed. It should be noted that the SPF was the focus of the analysis and the other three methods were included for comparison purposes. An NB (negative binomial) regression analysis was employed to apply the four methods to the study data, making comparison of the four methods consistent. The four methods and the NB regression analysis are described separately.

\subsection{Four Methods of Measuring Safety Performance}

Crash frequency (5-year crashes per segment), crash density (5-year crashes per mile) and crash rate (5-year crashes per 1,000 vehicles per mile) were employed to assess the safety performance of the four line marking types with a centerline and edge lines. A crash frequency being used as a safety performance measure means that

Table 1 Descriptive statistics of the narrow low-volume study roads in Virginia.

\begin{tabular}{|c|c|c|c|c|c|c|c|c|c|c|}
\hline \multirow{2}{*}{$\begin{array}{l}\text { Pavement } \\
\text { width }\end{array}$} & \multirow{2}{*}{ Line marking type } & \multirow{2}{*}{$\begin{array}{l}\text { Number of } \\
\text { segments }\end{array}$} & \multicolumn{4}{|c|}{ AADT (vehicles/day) } & \multicolumn{4}{|c|}{$\begin{array}{c}\text { Crash rate } \\
\text { (5-year crashes } / 1,000 \text { vehicle per mile) }\end{array}$} \\
\hline & & & Mean & $\begin{array}{l}\text { Standard } \\
\text { deviation }\end{array}$ & Minimum & Maximum & Mean & $\begin{array}{l}\text { Standard } \\
\text { deviation }\end{array}$ & Minimum & Maximum \\
\hline \multirow{4}{*}{$16 \mathrm{ft}$} & No lines & 118 & 371 & 335 & 24 & 1,402 & 3.37 & 17.1 & 0 & 175 \\
\hline & Centerline only & 21 & 664 & 295 & 140 & 1,025 & 5.33 & 5.02 & 0 & 16 \\
\hline & Edge lines only & 4 & 299 & 95 & 216 & 381 & 0.81 & 1.62 & 0 & 3 \\
\hline & Both lines & 56 & 967 & 675 & 94 & 2,896 & 4.03 & 6.06 & 0 & 31 \\
\hline \multirow{4}{*}{$18 \mathrm{ft}$} & No lines & 737 & 144 & 158 & 4 & 1,832 & 2.23 & 10.4 & 0 & 132 \\
\hline & Centerline only & 61 & 1,055 & 837 & 24 & 2,877 & 3.15 & 7.90 & 0 & 58 \\
\hline & Edge lines only & 9 & 286 & 508 & 60 & 1,632 & 3.30 & 9.45 & 0 & 28 \\
\hline & Both lines & 284 & 1,189 & 794 & 12 & 2,907 & 3.12 & 6.47 & 0 & 64 \\
\hline \multirow{4}{*}{$20 \mathrm{ft}$} & No lines & 1,226 & 200 & 263 & 3 & 2,463 & 0.94 & 11.2 & 0 & 352 \\
\hline & Centerline only & 157 & 1,472 & 634 & 76 & 2,893 & 1.45 & 2.56 & 0 & 12 \\
\hline & Edge Lines only & 5 & 808 & 0 & 808 & 808 & 0.35 & 0.78 & 0 & 2 \\
\hline & Both lines & 2,119 & 1,652 & 714 & 81 & 2,996 & 2.05 & 3.16 & 0 & 37 \\
\hline
\end{tabular}


segment length and traffic volume are unrelated to crash frequency. For example, a 1-mile segment carrying 1,000 vpd and a 10-mile segment carrying $10,000 \mathrm{vpd}$ are the same in their safety performance measured by the crash frequency as long as the two segments have the same number of crashes. However, it is generally understood that an increase in segment length and/or traffic volume is closely associated with a higher crash risk, leading to more crashes. Thus, although the crash frequency is straight forward to understand, it has a critical shortcoming of failing to take segment length and traffic volume into account.

Crash density assumes that a longer segment is proportionally related to a higher crash frequency. Thus, crash density addresses one of the shortcomings of crash frequency, which is a consideration of the safety effects of a segment length. However, traffic volume, a known influential factor on crash frequency, is still not taken into account. A crash rate with traffic volume being its denominator (e.g., crashes per 1,000 vehicles per mile) assumes that an increase in traffic volume, as well as segment length, is proportionally related to an increase in crash frequency. This certainly incorporates the safety effects of both segment length and traffic volume. However, the linearity assumption on traffic volume in relation to crash frequency (i.e., proportional relationship between traffic volume and crash frequency) imposed by the crash rate has often been found invalid. For example, many SPFs in Safety Analyst ${ }^{\mathrm{TM}}$ [9] and the HSM (Highway Safety Manual) [10] show a non-linear relationship between crash frequency and traffic volume.

\subsection{Negative Binomial Regression Model}

The four methods of measuring safety performance were applied through the NB regression approach that is considered to be standard for analyzing crash counts in relation to several influential factors (e.g., traffic volume and speed [11-14]). One NB model was developed for each of the four methods, and to compare the results of the four methods in a consistent manner, an identical model specification was employed for all the methods. The model specifications are shown as follows:

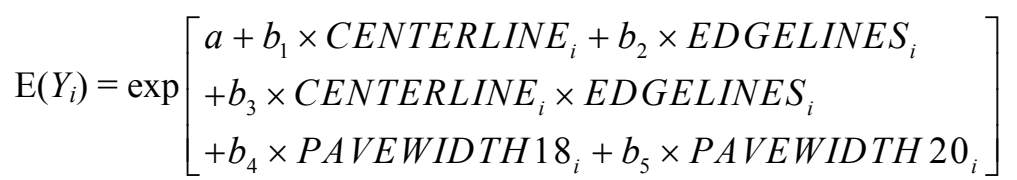

$$
\begin{aligned}
& \mathrm{E}\left(\text { Crash_Frequency }_{i}\right)=\exp \left[\begin{array}{l}
a+b_{1} \times \text { CENTERLINE }_{i}+b_{2} \times \text { EDGELINES }_{i} \\
+b_{3} \times C E N T E R L I N E_{i} \times E D G E L I N E S_{i} \\
+b_{4} \times \text { PAVEWIDTH } 18_{i}+b_{5} \times \text { PAVEWIDTH } 20_{i} \\
+b_{6} \times \ln A A D T_{i}+\ln \text { LENGTH }_{i}
\end{array}\right]
\end{aligned}
$$

where:

$i=$ segment index;

$\mathrm{E}=$ expectation;

$Y_{i}=$ safety performance measure of segment $i$ (i.e., crash frequency, density or rate);

CENTERLINE $_{i}=1$ if a centerline is present on segment $i$ and 0 otherwise;

EDGELINES $_{i}=1$ if edge lines are present on segment $i$ and 0 otherwise;

PAVEWIDTH $18_{i}=1$ if a pavement width of segment $i$ is $18 \mathrm{ft}$ and 0 otherwise;

PAVEWIDTH $20_{i}=1$ if a pavement width of segment $i$ is $20 \mathrm{ft}$ and 0 otherwise;

$A A D T_{i}=$ annual average daily traffic volume of segment $i$;

$\operatorname{LENGTH}_{i}=$ length of segment $i$;

$a, b_{1}, \ldots, b_{6}=$ coefficient parameters to be estimated.

For the SPF method, Eq. (2), two terms $(\ln A A D T$ and $\ln L E N G T H$ ) are added to Eq. (1) and $\ln L E N G T H$ has no corresponding coefficient parameter for being an 
offset.

To examine the safety performance of the line markings more thoroughly, an in-depth analysis was conducted using the SPF method. The study data were first split into 12 subsets, one for each pair of the three pavement widths $(16,18$ and $20 \mathrm{ft})$ and the four line marking types (no lines, a centerline only, edge lines only and both lines) and a separate SPF was developed for each subset. Because the pavement width and line marking type are identical within each subset, the model specification of the SPF includes $\ln A A D T$ as a sole explanatory variable. This analysis allows the safety effects of the different line markings to vary across the different pavement widths and over the range of AADTs.

\section{Results and Discussion}

The four NB regression models were developed for the four methods of measuring safety performance, one model for each method, and the model results are discussed here. The in-depth analyses using the SPF method were conducted for the 12 subsets of the study data to examine the potential variant safety performance of the line markings over the different pavement widths and AADTs and their results are discussed in a separate section.

\subsection{Four Methods of Measuring Safety Performances}

Four NB regression models were estimated for the four methods (crash frequency, crash density, crash rate and SPF), and their estimates are shown in Table 2, where the second through the last column correspond to the four methods, respectively: The last column corresponds to the SPF method where the crash frequency is a dependant variable and $\ln A A D T$ is included in a set of explanatory variables. A positive sign of coefficient estimates of the line marking variables indicates a higher value in the crash frequency, density or rate, which is expected when a corresponding line marking is present compared to the no-line condition. For example, the coefficients of CENTERLINE variable in all four models are positive and statistically significant at a 0.05 level. This means that a higher crash risk is predicted on a segment with a centerline only compared to no lines at $95 \%$ confidence level. The other line marking variables are statistically

Table 2 Results of NB regression models for the four methods.

\begin{tabular}{|c|c|c|c|c|c|c|c|c|}
\hline \multirow{3}{*}{ Independent variable } & \multicolumn{8}{|c|}{ Dependent variable } \\
\hline & \multicolumn{2}{|c|}{ Crash frequency $^{\mathrm{a}}$} & \multicolumn{2}{|c|}{ Crash density $^{\mathrm{a}}$} & \multicolumn{2}{|c|}{ Crash rate $^{\mathrm{a}}$} & \multicolumn{2}{|c|}{ Crash frequency $^{\mathrm{b}}$} \\
\hline & Coefficient & $p$-value & Coefficient & $p$-value & Coefficient & $p$-value & Coefficient & $p$-value \\
\hline Intercept & -1.355 & $<0.001$ & -0.436 & 0.007 & 1.088 & $<0.001$ & -3.466 & $<0.001$ \\
\hline CENTERLINE & 2.467 & 0.001 & 2.067 & $<0.001$ & 0.400 & 0.026 & 0.876 & $<0.001$ \\
\hline EDGELINES ${ }^{\mathrm{c}}$ & 0.639 & 0.284 & 0.132 & 0.829 & -0.035 & 0.955 & -0.459 & 0.351 \\
\hline CENTERLINE $\times$ EDGELINES $S^{\mathrm{d}}$ & -0.128 & 0.834 & 0.211 & 0.737 & 0.304 & 0.639 & 0.517 & 0.300 \\
\hline PAVEWIDTH $18^{\mathrm{c}}$ & -0.617 & $<0.001$ & -0.758 & $<0.001$ & -0.364 & 0.067 & -0.254 & 0.015 \\
\hline PAVEWIDTH $20^{\mathrm{c}}$ & -0.970 & $<0.001$ & -0.919 & $<0.001$ & -1.077 & $<0.001$ & -0.478 & $<0.001$ \\
\hline $\ln A A D T$ & \multicolumn{2}{|c|}{ NA } & \multicolumn{2}{|c|}{ NA } & \multicolumn{2}{|c|}{ NA } & 0.587 & $<0.001$ \\
\hline $\ln L E N G T H$ (offset) & \multicolumn{2}{|c|}{ NA } & NA & & \multicolumn{2}{|c|}{ NA } & 1.000 & NA \\
\hline Number of observations & \multicolumn{8}{|c|}{ 4,797 segments } \\
\hline \multicolumn{9}{|c|}{$\begin{array}{l}{ }^{a} \text { Crash frequency }=\text { number of crashes in five years; Crash density }=\text { number of crashes in five years per mile; Crash rate }=\text { number of } \\
\text { crashes in five years per } 1,000 \text { vehicles per mile; }\end{array}$} \\
\hline \multicolumn{9}{|c|}{$\begin{array}{l}{ }^{\mathrm{b}} \text { Crash frequency }=\text { number of crashes in five years per vehicle per mile. This column corresponds to the SPF, the crash frequency } \\
\text { being a function of } \ln A A D T \text { and } \ln L E N G T H \text { in addition to the line marking and width indicators; }\end{array}$} \\
\hline \multirow{2}{*}{\multicolumn{9}{|c|}{$\begin{array}{l}{ }^{\mathrm{c}} \text { An indicator variable equaling } 1 \text { if the condition is true: For example, CENTERLINE }=1 \text { if a centerline is presented in a segment and } \\
P A V E W I D T H 18=1 \text { if the pavement width of a segment is } 18 \mathrm{ft} \text {; }\end{array}$}} \\
\hline & & & & & & & & \\
\hline \multicolumn{9}{|c|}{$\begin{array}{l}\mathrm{d} \text { An interaction variable equaling } 1 \text { if both lines are present in a segment. The corresponding coefficient represents a differential effect } \\
\text { of the presence of both lines, meaning that all three line marking indicators including the interaction term should be combined to } \\
\text { produce a total safety effect of both lines. }\end{array}$} \\
\hline
\end{tabular}


insignificant even at $80 \%$ confidence level.

The detrimental effect of a centerline only is unexpected and counterintuitive, which prompted the in-depth SPF analysis discussed in the next section. A magnitude of the effect of a centerline only is substantial in the two methods (crash frequency and density) in that a segment with a centerline only is predicted to be about 12 and 8 times riskier than that with no lines for crash frequency and density, respectively, which is likely to be largely attributable to traffic volume difference (see Table 1). As described previously, however, these two methods fail to account for the varying safety effects of traffic volume. When the varying effects of traffic volume are incorporated by the crash rate and SPF methods, the magnitude becomes considerably lower, 1.5 and 2.4 times, respectively, yet the detrimental effect is still noted.

A segment with edge lines only is predicted to be riskier than that with no lines in all four methods yet it is not statistically significant at a 0.2-significance level, meaning that there is no statistical difference in safety performance between no lines and edge lines only. A segment with both lines is predicted to be riskier than that with a centerline only in the four methods yet it is not statistically significant at a 0.2-significance level. This means that adding edge lines to a segment with a centerline only is not statistically associated with improvement in safety performance in the four methods. Regarding the safety effects of pavement width, a wider pavement was found to be associated with a lower crash risk in all four methods at a 0.05-significance level except for the crash rate method, with a 0.1 -significance level.

For a better understanding of the safety performance of the four line markings, the predicted values of safety performance by the four methods were calculated based on the results of Table 2 and are provided in Table 3. A segment with a centerline only has considerably higher values in crash frequency and density in all three pavement widths. For example, for the 16 - $\mathrm{ft}$ pavement, a segment with a centerline only is predicted to have about 12 times more crashes (i.e., $3.04 \div 0.26$ ) and an 8-time higher crash density (i.e., $5.11 \div 0.65)$ than that with no lines, which is consistent with the direct inferences from Table 2.

\subsection{In-depth SPF Analysis}

Considerable detrimental effects of a centerline only

Table 3 Predicted safety performance measures by the four methods.

\begin{tabular}{|c|c|c|c|c|c|c|}
\hline \multirow{2}{*}{ Pavement width } & \multirow{2}{*}{ Line marking type } & \multirow{2}{*}{ Number of segments } & \multicolumn{4}{|c|}{ Four methods of measuring safety performance } \\
\hline & & & Crash frequency $^{\mathrm{a}}$ & Crash density $^{\mathrm{b}}$ & Crash rate $^{c}$ & $\mathrm{SPF}^{\mathrm{d}}$ \\
\hline \multirow{4}{*}{$16 \mathrm{ft}$} & No lines & 118 & 0.26 & 0.65 & 2.97 & 1.80 \\
\hline & Centerline only & 21 & 3.04 & 5.11 & 4.43 & 4.32 \\
\hline & Edge lines only & 4 & 0.49 & 0.74 & 2.87 & 1.14 \\
\hline & Both lines & 56 & 5.07 & 7.19 & 5.79 & 4.57 \\
\hline \multirow{4}{*}{$18 \mathrm{ft}$} & No lines & 737 & 0.14 & 0.30 & 2.97 & 1.80 \\
\hline & Centerline only & 61 & 1.64 & 2.40 & 4.43 & 4.32 \\
\hline & Edge lines only & 9 & 0.26 & 0.35 & 2.87 & 1.14 \\
\hline & Both lines & 284 & 2.73 & 3.37 & 5.79 & 4.57 \\
\hline \multirow{4}{*}{$20 \mathrm{ft}$} & No lines & 1,226 & 0.10 & 0.26 & 2.97 & 1.80 \\
\hline & Centerline only & 157 & 1.15 & 2.04 & 4.43 & 4.32 \\
\hline & Edge lines only & 5 & 0.19 & 0.29 & 2.87 & 1.14 \\
\hline & Both lines & 2,119 & 1.92 & 2.87 & 5.79 & 4.57 \\
\hline
\end{tabular}

${ }^{a}$ Average number of crashes in five years per segment;

${ }^{\mathrm{b}}$ Average number of crashes in five years per mile;

${ }^{c}$ Average number of crashes in five years per 1,000 vehicles per mile;

${ }^{\mathrm{d}}$ Average number of crashes in five years per 1,000 vehicles per mile. Predictions were made by the SPF assuming a 1-mile segment carrying $1,000 \mathrm{vpd}$. 
were found to be statistically significant in the previous analyses. However, those analyses were based on several assumptions including invariant effects of line markings across the different pavement widths and/or the range of AADTs. To examine the safety performance of the line markings more thoroughly, an in-depth analysis was conducted using the SPF method as described previously. SPFs for segments with edge lines only were developed, but their estimates are not presented because the results were deemed unreliable due to the small sample sizes: Only 4, 9 and 5 segments exist with 16,18 and $20 \mathrm{ft}$ of pavement, respectively. A total of nine estimated SPFs are presented in Table 4.

All parameter estimates are statistically significant at a 0.05 -significance level except for the intercept and $\ln A A D T$ for the segments where only a centerline is in place on a 16 -ft pavement and the coefficient estimate of $\ln A A D T$ is statistically significant at a 0.1 level. All the slope coefficients of $\ln A A D T$ appear to be different, varying from 0.490 (both lines on a 16 -ft pavement) to 1.011 (a centerline only on a 20-ft pavement), yet some might be statistically identical. With two slope estimates and their standard errors, it is possible to test if the two slopes are different using Welch's two-sample $t$-test [15], suitable for a case with unequal variances. The degree of freedom is approximated by the Welch-Satterthwaite equation [16].

Table 5 shows the results of the $t$-tests of the nine slope coefficients; Three of the nine comparing pairs of the three different line markings were found to be statistically identical in their coefficients: no lines versus a centerline only and both lines versus a centerline only for $16 \mathrm{ft}$ of pavement and no lines versus a centerline only for $18 \mathrm{ft}$ of pavement. This

Table 4 Results of in-depth SPF analysis.

\begin{tabular}{|c|c|c|c|c|c|c|c|}
\hline \multirow{3}{*}{ Line marking } & \multirow{3}{*}{ Independent variable } & \multicolumn{6}{|c|}{ Pavement width } \\
\hline & & \multicolumn{2}{|c|}{$16 \mathrm{ft}$} & \multicolumn{2}{|c|}{$18 \mathrm{ft}$} & \multicolumn{2}{|c|}{$20 \mathrm{ft}$} \\
\hline & & Coefficient & $p$-value & Coefficient & $p$-value & Coefficient & $p$-value \\
\hline \multirow{3}{*}{ No lines } & Intercept & -3.368 & $<0.001$ & -5.234 & $<0.001$ & -5.933 & $<0.001$ \\
\hline & $\ln A A D T$ & 0.594 & 0.011 & 0.917 & $<0.001$ & 0.860 & $<0.001$ \\
\hline & Number of segments & \multicolumn{2}{|c|}{118} & \multicolumn{2}{|c|}{737} & \multicolumn{2}{|c|}{1,226} \\
\hline \multirow{3}{*}{ Centerline only } & Intercept & -2.155 & 0.228 & -5.175 & 0.001 & -6.149 & $<0.001$ \\
\hline & $\ln A A D T$ & 0.511 & 0.066 & 0.916 & $<0.001$ & 1.011 & $<0.001$ \\
\hline & Number of segments & \multicolumn{2}{|c|}{21} & \multicolumn{2}{|c|}{61} & \multicolumn{2}{|c|}{157} \\
\hline \multirow{3}{*}{ Both lines } & Intercept & -1.983 & 0.047 & -2.329 & $<0.001$ & -2.281 & $<0.001$ \\
\hline & $\ln A A D T$ & 0.490 & 0.001 & 0.505 & $<0.001$ & 0.489 & $<0.001$ \\
\hline & Number of segments & \multicolumn{2}{|c|}{56} & \multicolumn{2}{|c|}{284} & \multicolumn{2}{|c|}{2,119} \\
\hline
\end{tabular}

The dependent variable is the crash frequency in five years and $\ln L E N G T H$ is included as an offset.

Table 5 Results of Welch's $t$-tests for slope coefficients.

\begin{tabular}{llcl}
\hline Pavement width & Comparing pair of line markings & $t$-statistics & $p$-value \\
\hline \multirow{3}{*}{$16 \mathrm{ft}$} & No lines vs. centerline only & 1.28 & 0.199 \\
& No lines vs. both lines & 3.56 & 0.000 \\
& Both lines vs. centerline only & 0.33 & 0.744 \\
\hline \multirow{2}{*}{$18 \mathrm{ft}$} & No lines vs. centerline only & 0.04 & 0.971 \\
& No lines vs. both lines & 65.61 & 0.000 \\
& Both lines vs. centerline only & 14.83 & 0.000 \\
\hline \multirow{2}{*}{$20 \mathrm{ft}$} & No lines vs. centerline only & 8.63 & 0.000 \\
& No lines vs. both Lines & 85.18 & 0.000 \\
\hline
\end{tabular}

Slope coefficients of $\ln A A D T$ of the nine safety performance functions (SPFs) shown in Table 3 are compared in pair by the line marking types with the same pavement width. 
means for the example of the pair of no lines versus a centerline only on a pavement with either $16 \mathrm{ft}$ or $18 \mathrm{ft}$ that the 5-year crash frequency is predicted to increase as AADT increases in the same rate on such segments with these two line marking types.

Tables 4 and 5 provide information useful to assess the safety performance of the line marking types. However, to derive interpretable assessment results, relative comparisons of the coefficient estimates should be made and it is difficult to make such comparisons directly from the model estimates in Table 4. To produce understandable safety assessment results, predicted numbers of the 5-year crashes were computed for a 1-mile segment carrying varying AADTs from 0 to $3,000 \mathrm{vpd}$ and are graphically presented in Fig. 1.

The three pairs of the line markings found to be statistically identical in Table 5 can be visually verified in Fig. 1 that the corresponding prediction curves (solid lines) are in parallel in each pair. For instance, all three prediction curves for the 16-ft pavement representing no lines, a centerline only and both lines are parallel. This implies that a single slope coefficient would be sufficient for the three curves while any difference among the three can be addressed by developing a calibration factor employed in the HSM [10].

For the 16-ft pavement, the prediction curves of both lines and a centerline only (in Fig. 1a) are very close while that of no lines is placed lower, meaning the predicted number of crashes for no lines is smaller than those of both lines and a centerline only when the length, pavement width and AADT of a segment are the same. However, the 95th percentile upper limits (dotted lines) suggest that the prediction curves of the three markings are statistically indistinguishable in that the prediction curves are below all the limits.

For the 18-ft pavement, only the prediction curves of no lines and a centerline curve (in Fig. 1b) are close while that of both lines is above the two curves at AADTs smaller than about 1,000 and below at AADTs greater than about 1,000 . This implies that a segment with either a centerline only or no lines is predicted to have fewer crashes than with both lines when carrying AADTs smaller than about 1,000 but more crashes when carrying AADTs greater than about 1,000. However, the prediction curves of the three markings are lower than all three upper limits. Thus the safety performance of the three markings is statistically identical when the segment length, pavement width and AADT are the same across the marking types.

For the 20-ft pavement, as shown in Fig. 1c, no lines was predicted to have fewer crashes than the other two line markings and both lines were predicted to have more crashes than a centerline only at AADTs smaller than about 1,700 and fewer crashes at AADTs greater than about 1,700 . When the upper prediction limits are considered, however, the differences in safety performance among the three markings disappear from a statistical standpoint. This means that, statistically, there is no difference in safety performance among the three line markings when the segment length, pavement width and AADT are controlled for. Therefore, the three line marking types (centerline only, both lines and no lines) do not show statistically different safety performances in terms of 5-year crash frequencies when the length, pavement width and AADT of a segment are taken into account.

It should be noted that including all types of crashes may not be appropriate for examining safety aspects of the line markings because certain types, such as animal collisions, may not be associated with the presence of line markings. Thus analyses similar to those performed for all crashes were performed on four crash types excluding types deemed not very relevant to the line markings and the four types are: (1) crashes excluding those colliding with a train, wild animals or pedestrians, those involving vehicles backing and unclassified types (Target Crash Type 1); (2) Target Crash Type 1 excluding rear-end crashes (Target Crash Type 2); (3) Target Crash Type 2 excluding angle crashes (Target Crash Type 3); (4) roadway departure crashes (Target Crash Type 4). There found 

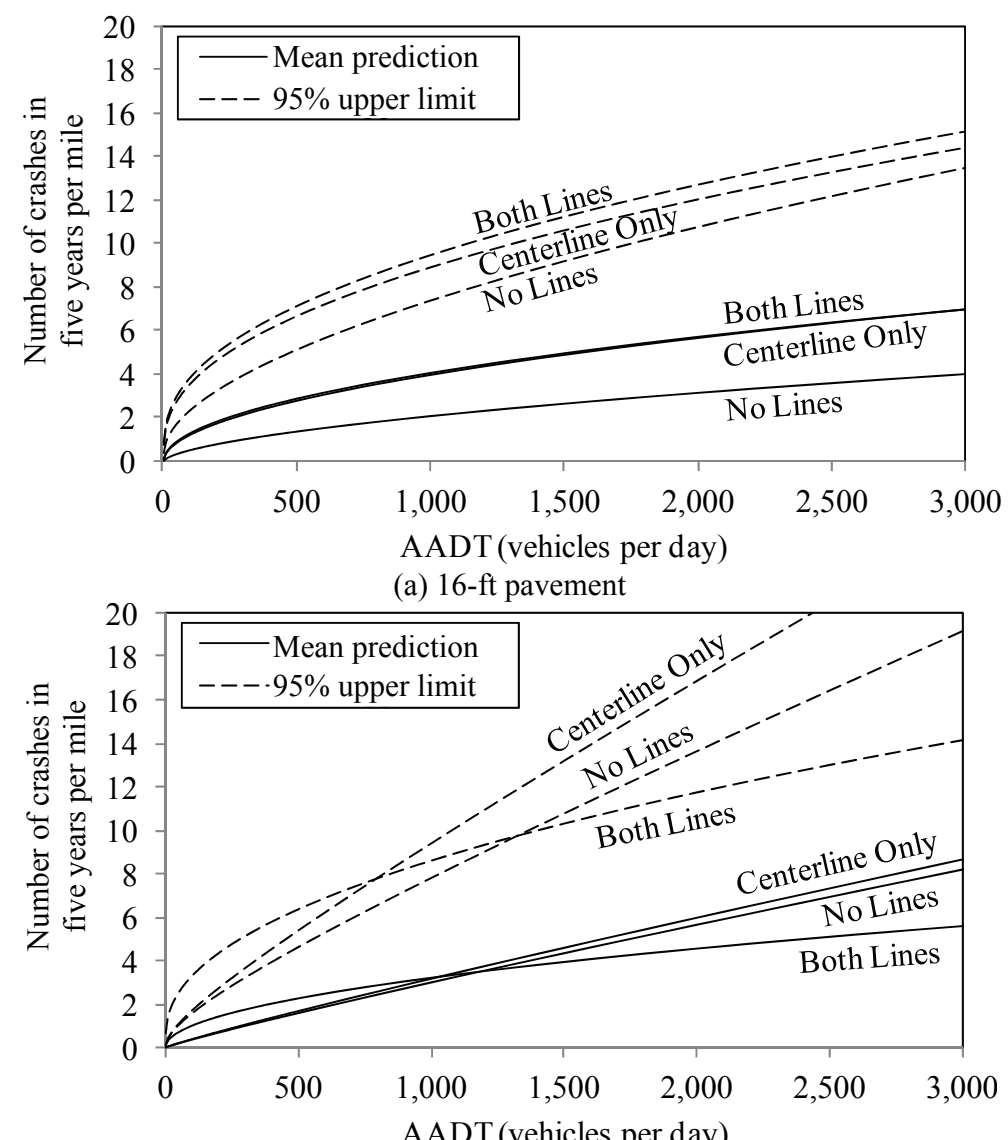

AADT (vehicles per day)

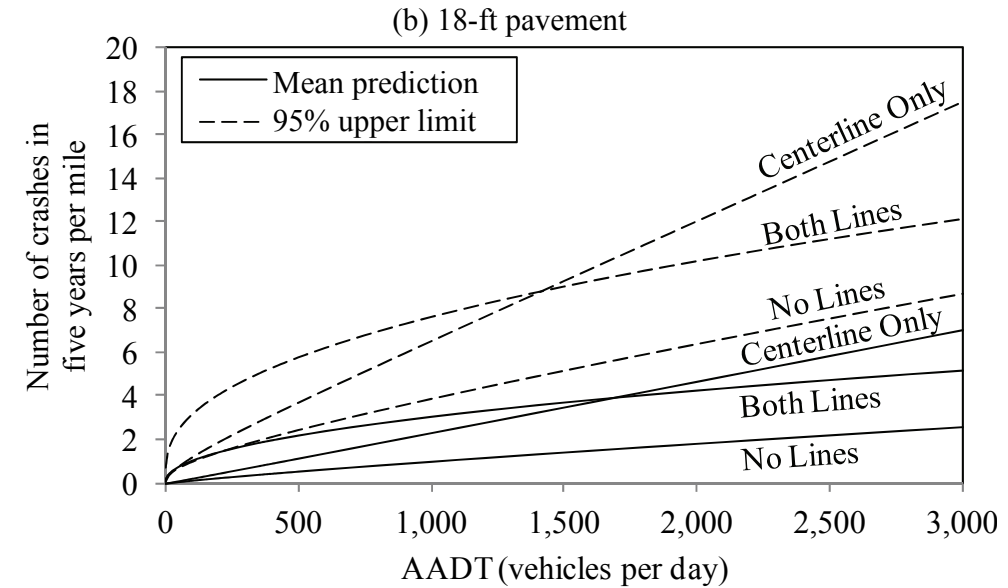

(c) 20-ft pavement

Fig. 1 Predictions and limits of 5-year crash frequencies on low-volume narrow roads in Virginia by line markings in three pavements: (a) 16-ft; (b) 18-ft; (c) 20-ft. Dotted lines represent the 95th percentile upper limits of mean predictions. The results of edge lines only are not presented because of the small sample sizes.

some differences in analysis results between all crashes and the four target crash types, yet the conclusions drawn from the different results are the same. Among all statistically significant results, these roads showed the largest differences in in-depth SPF analyses across the crash types and Fig. 2 shows the SPFs of all five crash types on these roads. As seen in Fig. 2, all the curves are almost parallel meaning the patterns of changes in the predicted crash frequency corresponding to changes in AADT are similar across all the crash types.

It should be noted that many potential influential 


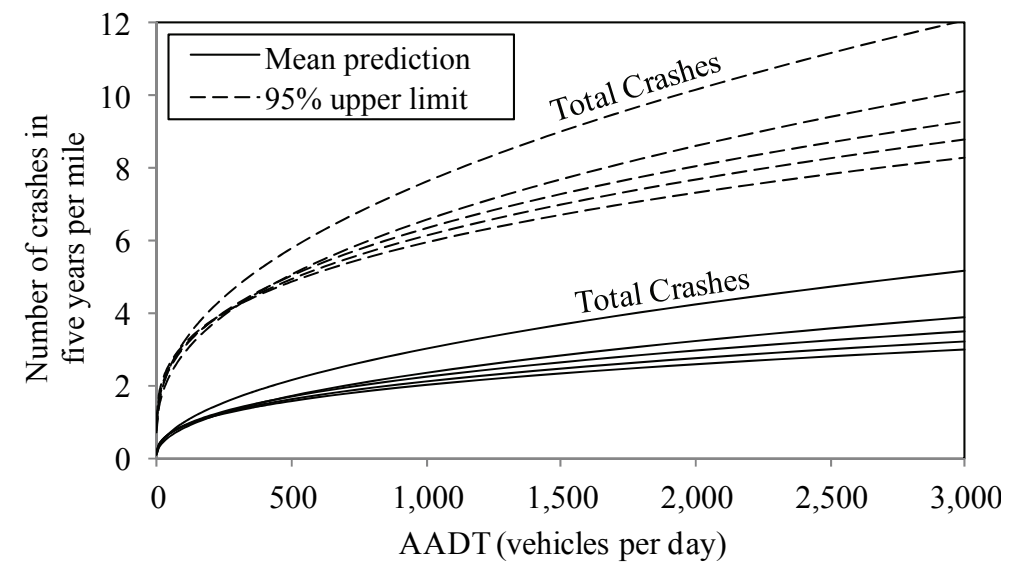

Fig. 2 Predictions and limits of 5-year crash frequencies on low-volume roads with 20-ft width and both lines in Virginia by crash types. Dotted lines represent the 95th percentile upper limits of mean predictions.

Four lines under total crashes correspond to Target Crash Types 1 (top) through Target Crash Types 4 (bottom).

factors other than segment length, pavement width and AADT exist, including horizontal curvature, traveling speed, driving behavior and population of drivers on these roads, and some of them might be strongly related to the crash frequency for these roads. Omitting important influential factors from analysis is likely to distort the results of the SPFs at least to some extent. For example, motorists may typically travel segments with edge lines and/or a centerline at a higher speed possibly because of the enhanced visual guidance of these travel ways compared to those with no lines. If this were true for the segments included in this study and a higher speed was found to be detrimental to the safety of the segments, the prediction curve of edge lines only, a centerline only or both lines would be placed lower than that of no lines when traveling speed is controlled for, which might lead to a conclusion regarding the safety benefits of edge lines, a centerline or both compared to no lines. To explore the potential influence of omitted factors, characteristics of crashes, vehicles and occupants in the study data were examined and the potential factors examined include driver's gender and age, number of vehicles involved (e.g., single and multiple-vehicle crashes), surface condition (e.g., dry, wet, snowy and icy), driver's action (e.g., exceed speed limit) and also combinations of these factors, such as age by gender and single-vehicle crashes on dry vs. non-dry surfaces. We found interesting results on cases when data are stratified by driver age and confounding effects of driver age is discussed in the next section.

\subsection{Confounding Effects of Driver Age}

When the age distribution of drivers involved in crashes was compared across the four line marking types, teen drivers appeared to be overrepresented in crashes on the segments with no lines compared to those with one or both lines. For example, 32\% of drivers involved in crashes on the segments with no lines were teenagers and $19 \%$ of drivers were teenagers on the segments with both lines. Other age groups showed similar proportions across the four marking types. For example, $30 \%$ of drivers in crashes on the segments with no lines were aged 20 34 and the same percentage was found on those with both lines.

However, this overrepresentation of crash-involved teen drivers on the low-volume narrow roads with no lines does not necessarily mean that such roads pose a higher crash risk for teen drivers than those with any line. It might be attributable to either (1) varying levels of use of the roads by different age groups of drivers (e.g., teen drivers are more likely to drive on the roads with no lines than on those with both lines) or (2) varying crash risks for teen drivers across the roads with different line markings (e.g., teen drivers are more likely to get involved in crashes on the roads with no 


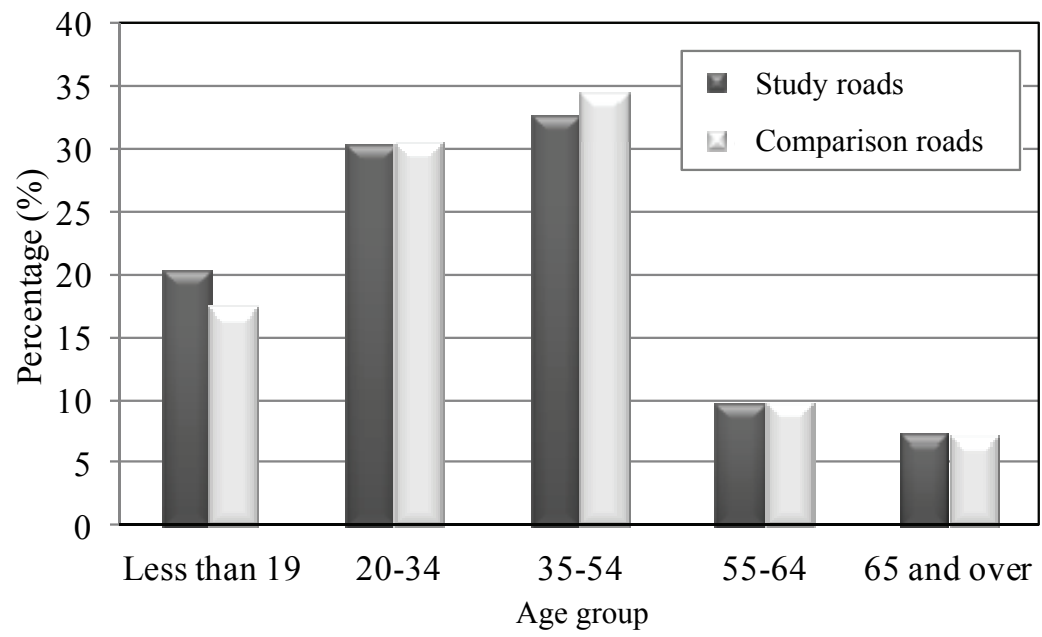

Fig. 3 Age distribution of drivers in crashes on the study and comparison roads in Virginia (2004 2008). The study and comparison roads are rural two-lane two-way undivided roads; The study roads carry 3,000 vpd or less and the comparison roads carry more than 3,000 vpd.

lines than on those with both lines).

Ideally, an age distribution of the driving population needs to be obtained for each of the four line marking types so that the source of the teen overrepresentation found in the study data can be investigated. However, no such data were available at the time of the study. As an alternative, characteristics of crashes on roads similar to the study roads yet carrying a higher traffic volume (more than 3,000 vpd) were collected and compared against characteristics of crashes on the study roads. As shown in Fig. 3, the age distribution of drivers in crashes on the higher volume narrow roads, called comparison roads, was found to be similar to that on the study roads, i.e., the low-volume narrow roads. In examining age distributions by different factors, such as road surface condition, lighting conditions and roadway departure status, similar comparison results were found between the two road groups. Therefore, an inference can be drawn that the degree of road use by drivers of different ages would be similar between the two road groups, which gives credence to the second possibility, i.e., teen drivers are more likely to get involved in crashes on roads with no lines than on roads with a centerline and/or both lines.

McKnight, A. J. and McKnight, A. S. [17] found that "cluelessness" (e.g., errors in attention, visual search and hazard recognition) rather than "carelessness" was a contributing factor in non-fatal traffic crashes involving teen drivers based on analyses of 2,000 crashes involving teen drivers in California and Maryland. Centerline and edge lines are intended to enhance visual clues for safe driving, and it might be plausible to infer that the absence of a centerline and/or edge lines on low-volume narrow roads appears to be associated with more crashes involving teen drivers, and thus the presence of a centerline and/or edge lines can be argued to be beneficial for this age group of drivers.

\section{Conclusions}

Based on the results of the in-depth analyses using the SPF method controlling for traffic volume and segment length, the study found no statistical difference in the safety performance between low-volume (i.e., 3,000 vpd or less) narrow (20 ft or less pavement width) roads with and without a centerline and/or edge lines. However, potential influential factors, such as curvature and traveling speeds, with regard to the crash frequency for these roads were not accounted for in the study. Including such factors in the analysis might lead to different findings regarding the safety effects of a centerline 
and/or edge lines.

In an examination of the potential effects of confounding factors omitted from the analyses, teen drivers were found to be overrepresented in crashes on the roads with no lines compared to those with one or both lines. By comparing the age distribution of drivers in crashes on the study roads against that on similar roads carrying a higher traffic volume, it was inferred that the extent of road use by drivers of different ages between the two compared road groups was similar. This further implies that teen drivers are more likely to get involved in crashes on roads with no lines than on roads with a centerline and/or both lines.

Since a centerline and/or edge lines would enhance visual clues for safe driving, these lines can be plausibly inferred to provide safety benefits for teen drivers.

\section{Acknowledgments}

The authors thank VDOT for sponsoring this study. Any views or opinions presented in this paper are solely those of the authors' and do not necessarily represent the views of VDOT.

\section{References}

[1] FHWA (Federal Highway Administration). 2012. Manual on Uniform Traffic Control Devices for Streets and Highways. Washington, D.C.: U.S. Department of Transportation.

[2] Tsyganov, A. R., Machemehl, R. B., and Warrenchuck, N. M. 2005. Safety Impact of Edge Lines on Rural Two-Lane Highways. CTR Report 0-5090-1, Center for Transportation Research, The University of Texas at Austin.

[3] Tsyganov, A. R., Machemehl, R. B., Warrenchuck, N. M, and Wang, Y. 2006. Before-After Comparison of Edge Line Effects on Rural Two-Lane Highways. CTR Report 0-5090-2, Center for Transportation Research, The University of Texas at Austin.

[4] Sun, X., and Tekell, V. O. 2005. Impact of Edge Lines on Safety of Rural Two-Lane Highways. Report No. 414, Louisiana Transportation Research Center, University of Louisiana at Lafayette.

[5] Kusano, K. D., and Gabler, H. C. 2012. "Rural Road Departure Crashes: Why Is Injury Severity Correlated with Lane Markings?.” In TRB 91st Annual Meeting
Compendium of Papers DVD. Washington, D.C.: Transportation Research Board of the National Academies, $1-12$.

[6] Van Driel, C. J. G., Maarseveen, M. F. A. M., and Davidse, R. J. 2004. "The Effects of an Edge Line on Speed and Lateral Position: A Meta-Analysis." Accident Analysis and Prevention 36 (4): 671-82.

[7] VDOT (Virginia Department of Transportation). 2011. Virginia Supplement to the 2009 Manual of Uniform Traffic Control Devices for Streets and Highways. Richmond: VDOT.

[8] Dougald, L. E., Cottrell, B. H., Kweon, Y. J., and Lim, I. K. 2013. Investigation of the Safety Effects of Edge and Centerline Markings on Narrow, Low-Volume Roads. Publication VCTIR 14-R3. Charlottesville: Virginia Center for Transportation Innovation and Research,

[9] AASHTO (Association of State Highway and Transportation Officials). 2013. Exelis Inc. Safety Analyst User's Manual. Washington, D.C.: AASHTO.

[10] AASHTO (Association of State Highway and Transportation Officials). 2010. Highway Safety Manual: 1st Edition. Washington, D.C.: AASHTO.

[11] Kweon, Y. J., Lim, I. K., Turpin, T., and Read, S. 2014. "Development and Application of Guidance to Determine the Best Way to Customize the Highway Safety Manual for Virginia." Transportation Research Record: Journal of the Transportation Research Board. (in press)

[12] Kweon, Y. J., and Lim, I. K. 2014. Development of Safety Performance Functions for Multilane Highway and Freeway Segments Maintained by the Virginia Department of Transportation. Publication VCTIR 14-R14. Charlottesville: Virginia Center for Transportation Innovation and Research.

[13] Lim, I. K., and Kweon, Y. J. 2013. "Identifying High-Crash-Risk Intersections: Comparison of Traditional Methods with the Empirical Bayes-Safety Performance Function Method." Transportation Research Record: Journal of the Transportation Research Board 2364: 44-50.

[14] Kweon, Y. J., and Lim, I. K. 2012. "Appropriate Regression Model Types for Intersections in Safety Analyst." Journal of Transportation Engineering 138 (10): 1250-8.

[15] Welch, B. L. 1947. "The Generalization of 'Student's' Problem When Several Different Population Variances Are Involved." Biometrika 34 (1-2): 28-35.

[16] Satterthwaite, F. E. 1946. “An Approximate Distribution of Estimates of Variance Components." Biometrics Bulletin 2: 110-4.

[17] McKnight A. J., and McKnight A. S. 2003. "Young Novice Drivers: Careless or Clueless?." Accident Analysis and Prevention 35 (6): 921-5. 